\title{
EXPLORATORY DATA ANALYSIS ON MACROSCOPIC MATERIAL BEHAVIOR USING MICROMECHANICAL SIMULATIONS BY APPLYING THE GAUSSIAN PROCESSES WITH VARIOUS KERNELS
}

\author{
Dr.R.Venkatesh Babu¹, Dr.G.Ayyappan², Dr.A.Kumaravel ${ }^{3}$ \\ Pro Vice Chancellor, Galgotias University, Greater Noida, Uttar Pradesh, India. ${ }^{1}$ \\ Associate Professor, Department of Information Technology, Prince Shri Venkateshwara Padmavathy Engineering \\ College, Chennai. ${ }^{2}$ \\ Professor, Dean School of Computing, Bharath Institute of Higher Education and Research, Chennai. ${ }^{3}$ \\ rvbaboo76@gmail.com ${ }^{1}$, ayyappangmca@gmail.com² ${ }^{2}$ drkumaravel@gmail.com ${ }^{3}$
}

\begin{abstract}
New materials can bring about tremendous progress in technology and applications. However, the commonly used trial-and-error method cannot meet the current need for new materials. Now, a newly proposed idea of using deductive learning to explore new materials is becoming popular. Deductive learning finds the hidden information in a database. This research work emphases on the capturing the macroscopic material behavior and their relations with the micromechanical simulations are trains the Deductive Learning algorithms. The quality of the Deductive Learning algorithms are only as good as that of the micromechanical model and it is need to validate the new model. It is proposing a novel deductive learning approaches to model macroscopic material behavior using micromechanical simulations to capture the mechanical reply of a variety of microstructures under dissimilar loads.
\end{abstract}

Keywords: Puk, Macroscopic Material, RBFKernel, Micromechanical simulations, Polykernel and Gaussian Processes.

\section{Introduction}

Deductive learning is a new field of AI. It Focuses on optimizing computer packages to enhance algorithms processing with records on information warehouse. DL has come to be an efficient and vital device for studying current substances in the subject of recent cloth discovery. Considering the intake of experimental improvement, the traditional fabric discovery technique can infrequently adapt to the huge-scale call for novel excessive overall performance materials. The input information consist of different strain-strain curves acquired from micromechanical simulations of uniaxial trying a huge variety of microstructures. Most of the techniques that arise in nature are loads of complicated to analyze, have plenty of self-governing parameters, and occasionally even the interrelation between parameters is unknown. It is the focus of current work to comprehensively analyze the interplay among the availability of materials statistics and the predictive capability of DL fashions.

This paper is structured as follows: First, the review of literature presented in section 2 . In section 3 , materials and methods are described. In section 4, the results and discussions have given. Finally, the conclusion is given in section 5.

\section{Literature Survey}

In this section focuses on the related works have done in this research field. here Is growing hobby in applying device gaining knowledge of techniques inside the research of materials technology.[1] However, although it is recognized that materials datasets are generally smaller and occasionally more various in comparison to different fields, [2-4] the influence of availability of substances information on education gadget studying fashions has no longer but been studied, which prevents the opportunity to establish correct predictive rules the usage of small substances datasets. [57] Here we analyzed the essential interplay among the provision of substances statistics and the predictive capability 
of the machine getting to know fashions. In the beyond few a long time, the tremendous advancement of the machine getting to know (ML) has spanned the utility of these records pushed technique during science, commerce, and industry.[8] Recently, there was a growing interest in applying ML to resolve problems in materials technology.[9] In unique, ML strategies have been used to represent inorganic substances,[10] expect fundamental residences,[11] create atomic ability,[12]pick out useful applicants,[13] examine complex reaction networks,[14] and manual experimental design.[15 \& 17-19] A substantial amount of programs of deductive studying techniques in materials science lies inside the area of microstructure category.[16] However, it's miles past the scope of this newsletter to offer a complete literature evaluation on this subject matter.

\section{Materials and Methods}

In this segment affords the materials and methods of this study's paintings. The dataset borrowed from homogenization of harm evolution from micro - to macro scale. (https://www.Frontiersin.Org/articles/10.3389/fmats.2019.00181/complete\#supplementary-fabric). It is composed 3454 instances and 8 attributes like harm parameter (D), a charge of damage parameter, equal plastic pressure, price of equal plastic pressure, equivalent total, equivalent elastic strain, von Mises strain, hydrostatic stress. It describes in the table1. Based on these parameters a ramification of loading states are replicated to build the database appropriate for harm taking place beneath popular repetitive loading paths.[16]

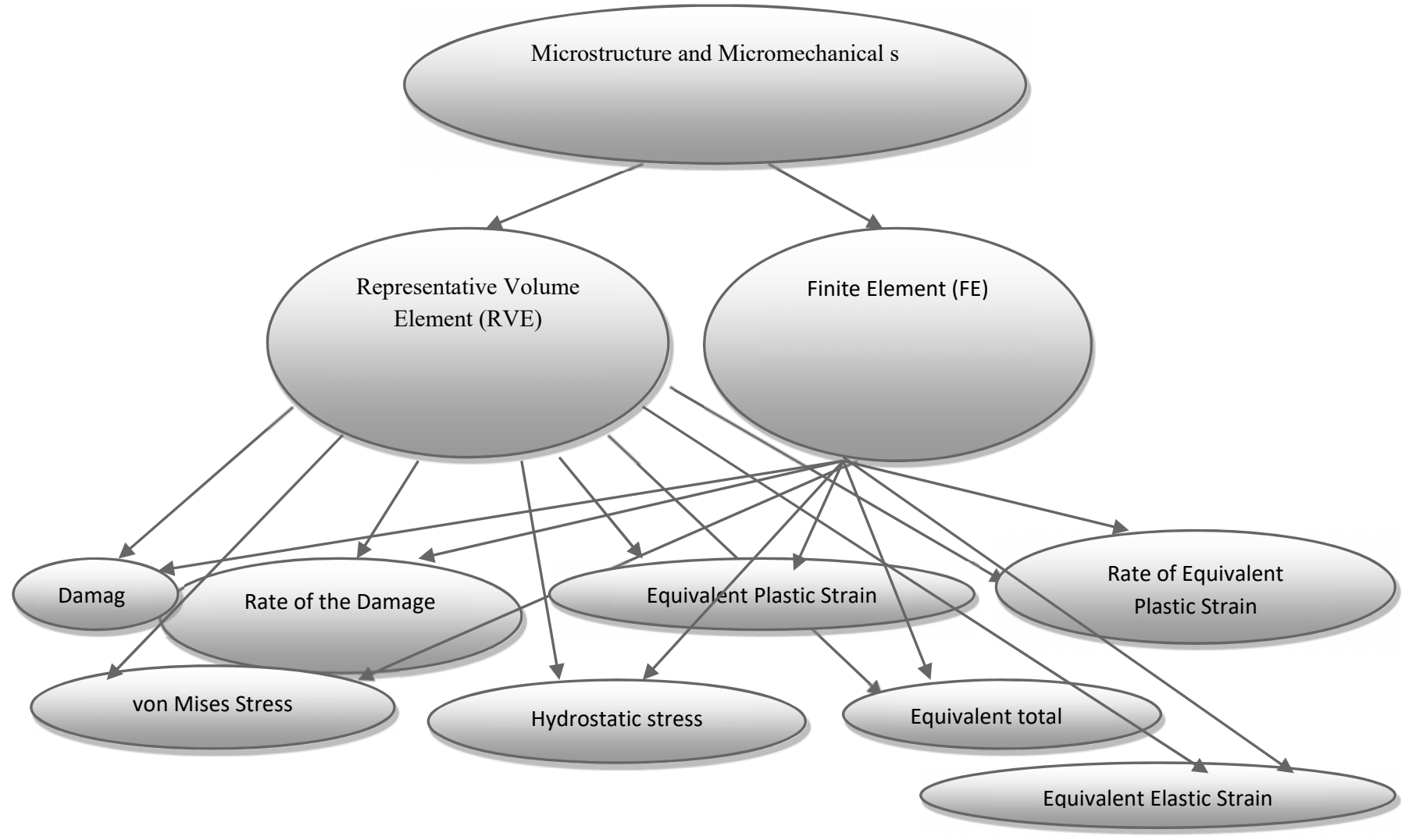

Figure1: Ontology of proposed system

In this research work one of the machine learning tools has implemented which is Weka 3.8.3. It gives more efficiency and easy to access the various ensemble machine learning algorithms compare with other tools. 
Table 1: Dataset Descriptions with Statistical Information

\begin{tabular}{|c|c|c|c|c|c|c|c|c|}
\hline S.No & $\begin{array}{l}\text { Name of the } \\
\text { Attribute }\end{array}$ & $\begin{array}{l}\text { Acronym of } \\
\text { the attribute }\end{array}$ & Data type & Unique & Min & Max & Mean & $\begin{array}{l}\text { Standard } \\
\text { Deviation }\end{array}$ \\
\hline 1 & $\mathrm{D}[-]$ & $\begin{array}{l}\text { Damage } \\
\text { Parameter }\end{array}$ & Numeric & $\begin{array}{c}552 \\
(16 \%)\end{array}$ & 0 & 0.39 & 0.02 & 0.06 \\
\hline 2 & D_dot $[1 / \mathrm{s}]$ & $\begin{array}{l}\text { Rate of the } \\
\text { Damage } \\
\text { Parameter }\end{array}$ & Numeric & $\begin{array}{c}552 \\
(16 \%)\end{array}$ & 0 & 0.39 & 0.02 & 0.06 \\
\hline 3 & $\mathrm{p}[-]$ & $\begin{array}{l}\text { Equivalent } \\
\text { Plastic Strain }\end{array}$ & Numeric & $\begin{array}{c}573 \\
(17 \%)\end{array}$ & 0 & 0.34 & 0.09 & 0.08 \\
\hline 4 & $\mathrm{p} \_\operatorname{dot}[1 / \mathrm{s}]$ & $\begin{array}{c}\text { Rate of } \\
\text { Equivalent } \\
\text { Plastic Strain }\end{array}$ & Numeric & $\begin{array}{c}574 \\
(17 \%)\end{array}$ & 0 & 0.94 & 0.1 & 0.04 \\
\hline 5 & Mises[MPa] & $\begin{array}{c}\text { von Mises } \\
\text { Stress }\end{array}$ & Numeric & $\begin{array}{c}582 \\
(17 \%)\end{array}$ & 50.93 & 393.00 & 357.04 & 26.80 \\
\hline 6 & Hydro[MPa] & $\begin{array}{l}\text { Hydrostatic } \\
\text { stress }\end{array}$ & Numeric & $\begin{array}{c}582 \\
(17 \%)\end{array}$ & 50.93 & 393.00 & 357.04 & 26.80 \\
\hline 7 & teq[-] & $\begin{array}{l}\text { Equivalent } \\
\text { total }\end{array}$ & Numeric & $\begin{array}{c}582 \\
(17 \%)\end{array}$ & 0 & 0.347 & 0.09 & 0.08 \\
\hline 8 & eeq[-] & $\begin{array}{c}\text { Equivalent } \\
\text { Elastic Strain }\end{array}$ & Numeric & $\begin{array}{c}580 \\
(17 \%)\end{array}$ & 0 & 0.002 & 0.002 & 0 \\
\hline 9 & LoadingState & $\begin{array}{c}\text { The Range } \\
\text { between } 0 \text { to } \\
8\end{array}$ & Numeric & 0 & 0 & 8 & 4.255 & 2.50 \\
\hline
\end{tabular}




\section{Methods}

In this research work implements various machine learning algorithms to find best model and evaluate all model by comparing various measurements.

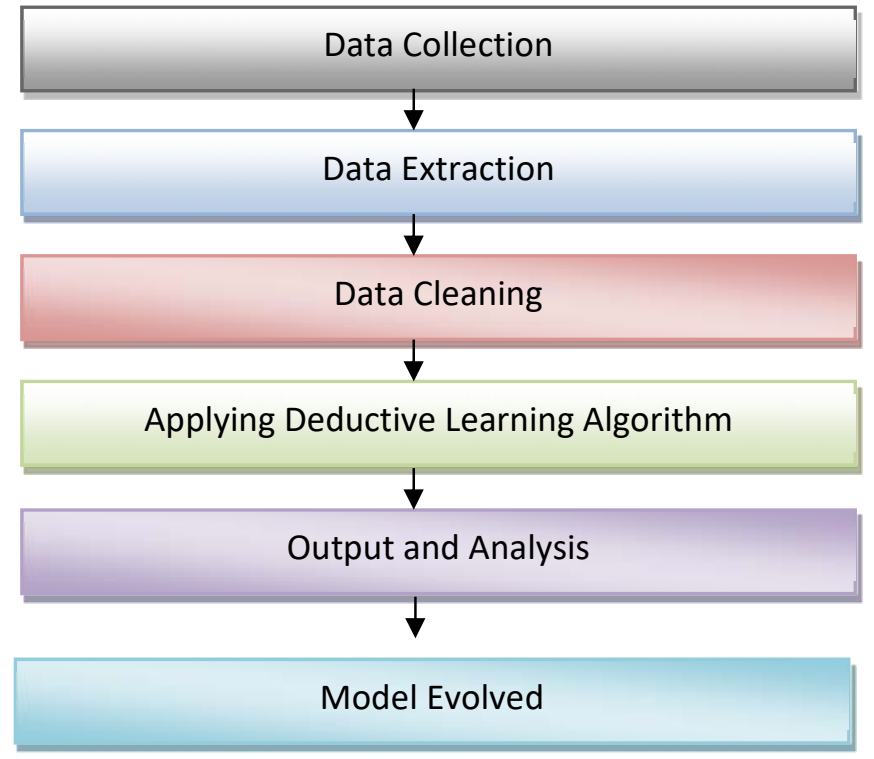

Figure 2: Architecture of Proposed System

The above machine learning algorithms applied in this research work and evaluates these model performances.

The Gaussian Processes learning with various kernels (Puk, RBFKernel and Polykernel) are applied in this research work.

\section{Results and Discussions}

In this section presents the results and discussions of this research work. The machine learning algorithm namely Gaussian Processes with various kernels. It has given the various measurements like Correlation Co Efficient (COE), Time taken to build model (Measured in Seconds) (T), Mean Absolute Error (MAE), Root Mean Squared Error(RMSE), Relative Absolute Error (RAE) and Root Relative Squared Error (RRSE).

Table 2: Various Measurements for Gaussian Processes with Different Kernels

\begin{tabular}{|l|l|l|l|l|l|l|l|}
\hline Classification & Kernel & $\begin{array}{l}\text { Correlation } \\
\text { Coefficient }\end{array}$ & $\begin{array}{l}\text { Mean } \\
\text { Absolute } \\
\text { Error }\end{array}$ & $\begin{array}{l}\text { Root } \\
\text { Mean } \\
\text { Squared } \\
\text { Error }\end{array}$ & $\begin{array}{l}\text { Relative } \\
\text { Absolute } \\
\text { Error }\end{array}$ & $\begin{array}{l}\text { Root } \\
\text { relative } \\
\text { squared } \\
\text { error }\end{array}$ & $\begin{array}{l}\text { Time Taken to } \\
\text { build the model } \\
\text { (In Seconds) }\end{array}$ \\
\hline \multirow{2}{*}{$\begin{array}{l}\text { Gaussian } \\
\text { Processes }\end{array}$} & Polykernel & 0.39 & 1.98 & 2.31 & $91.88 \%$ & $92.23 \%$ & 79.83 \\
\cline { 2 - 8 } & Puk & 0.92 & 0.79 & 1.06 & $36.62 \%$ & $42.21 \%$ & 77.2 \\
\cline { 2 - 7 } & RBFKernel & 0.29 & 2.05 & 2.40 & $94.96 \%$ & $95.82 \%$ & 82.05 \\
\hline
\end{tabular}

The above table represents that the various measurements while applying the Gaussian Processes with Polykernel produces the Correlation Coefficient is 0.39, Mean Absolute Error Value is 1.98, Root Mean Squared Error Value is 2.31, Relative Absolute Error value is 91.88\%, Root Relative Squared Error value is 92.23\% and building of this model has taken the time consumption is 79.83 seconds.

While applying the Gaussian Processes with Puk kernel algorithm, this model produces the Correlation Coefficient is 0.92, Mean Absolute Error Value is 0.78, Root Mean Squared Error Value is 1.06, Relative Absolute Error value is $36.62 \%$, Root Relative Squared Error value is $42.21 \%$ and building of this model has taken the time consumption is 77.2 seconds. 
While applying the Gaussian Processes with RBF kernel produces the Correlation Coefficient is 0.29, Mean Absolute Error Value is 2.05, Root Mean Squared Error Value is 2.40, Relative Absolute Error value is 94.96\%, Root Relative Squared Error value is $95.82 \%$ and building of this model has taken the time consumption is 82.05 seconds.

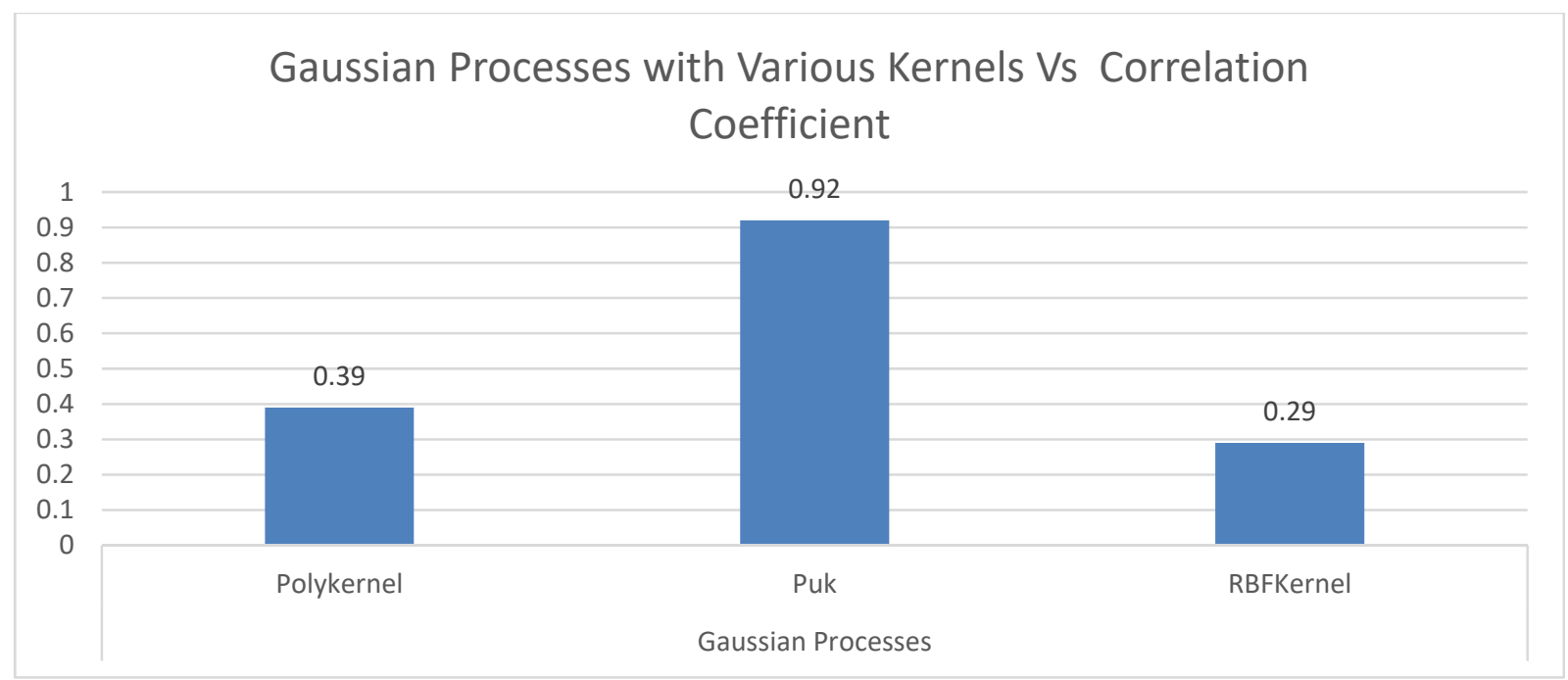

Figure 3: Gaussian Processes with Various Kernels Vs Correlation Coefficient

The above diagram clearly shows that the highest correlation coefficient value is 0.92 which is produced by Gaussian Processes with PUK kernel. The next highest correlation coefficient value is 0.39 which is produced by Gaussian Processes with Polykernel. The Weakest correlation coefficient value is produced by Gaussian Process with RBFKernel which is 0.29 .

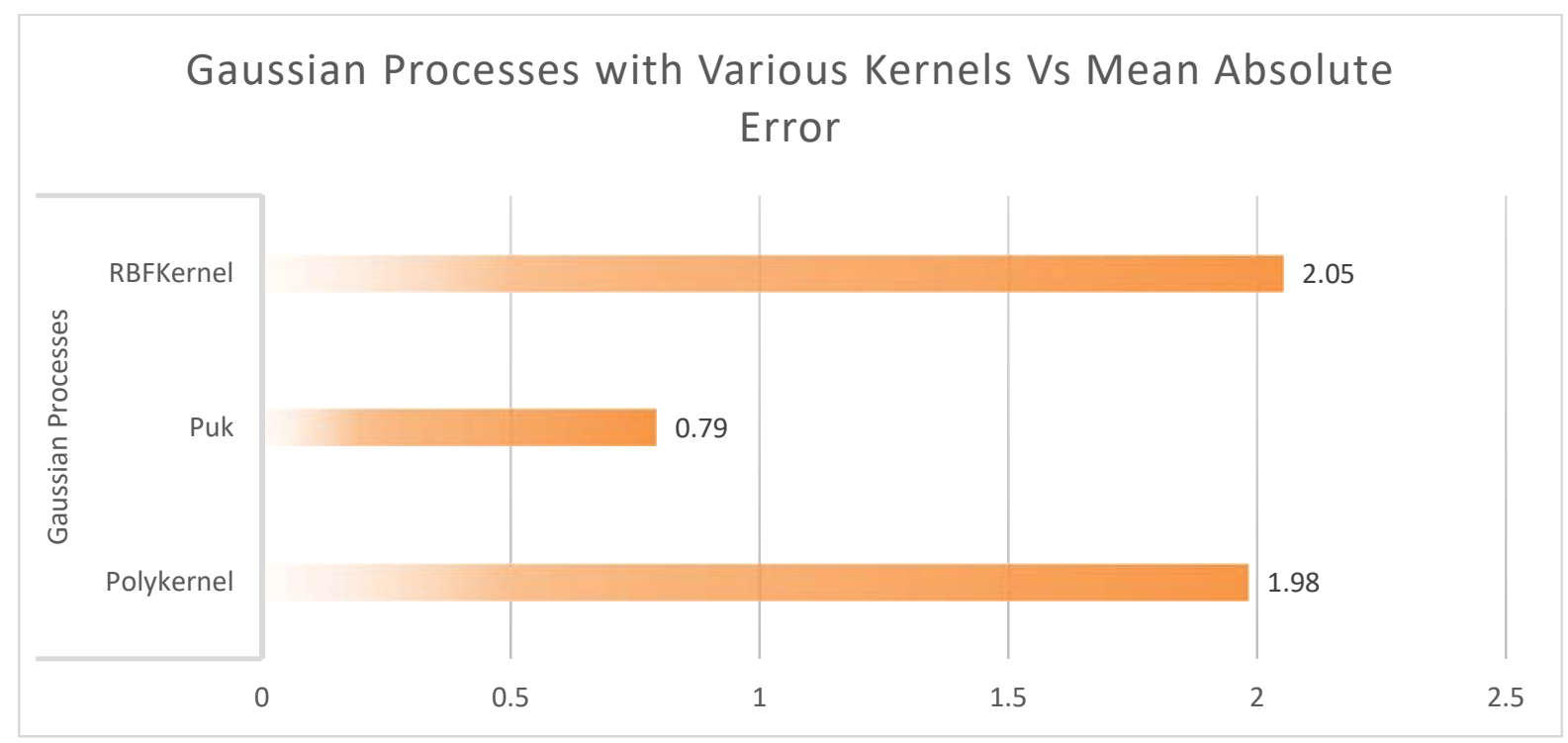

Figure 4: Gaussian Processes with Various Kernels Vs MAE

The above diagram represents that the Gaussian Approaches with PUK kernel produces the mean absolute error value is 0.79 . Comparatively this Mean absolute error value is very low while applying the other kernels in Gaussian Approaches. They are 2.05,1.98 for RBFKernel, Polykernel respectively. 


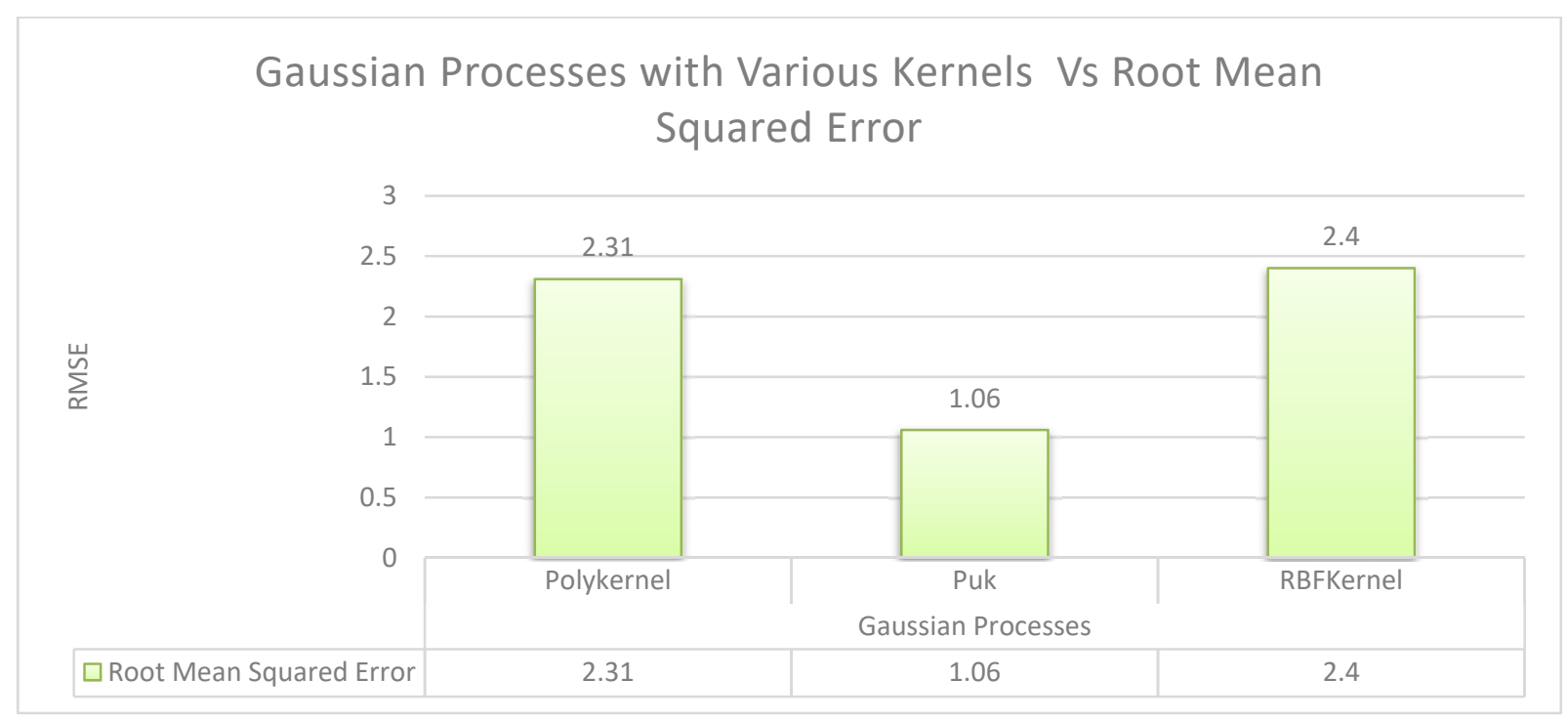

Figure 5: Gaussian Processes with Various Kernels Vs RMSE

The above diagram represents that the Gaussian Processes with RBFkernel produces highest Root Mean Squared Error which is 2.4. Others are Polykernel produces 2.31 and Puk kernel produces 1.06 for Root mean square error value.

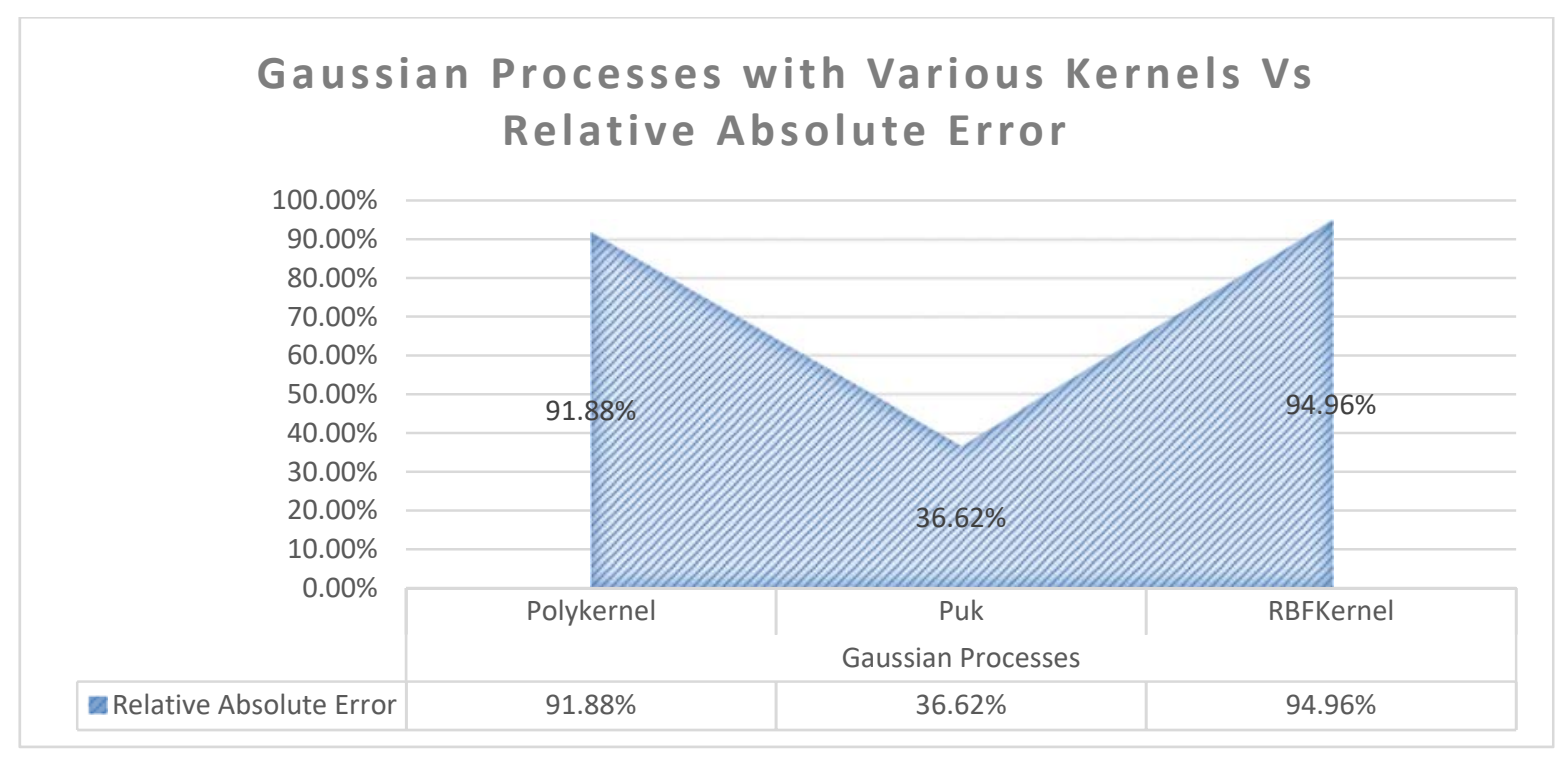

Figure 3: Gaussian Processes with Various Kernels Vs RAE

The above diagram represents that the Gaussian with Puk Kernel approaches produces the very low 36.62\% Relative Absolute Error. Other models are having the high Relative Absolute Error which are $91.88 \%$ of Polykernel and $94.96 \%$ of RBFKernel repectively. 


\section{Gaussian Processes With Various Kernels VS Root Relative Squared Error \\ VS Root Relative Squared Error}

\section{$120.00 \%$}

$100.00 \%$

$80.00 \%$

$60.00 \%$

$40.00 \%$

$20.00 \%$

$0.00 \%$

$\%$

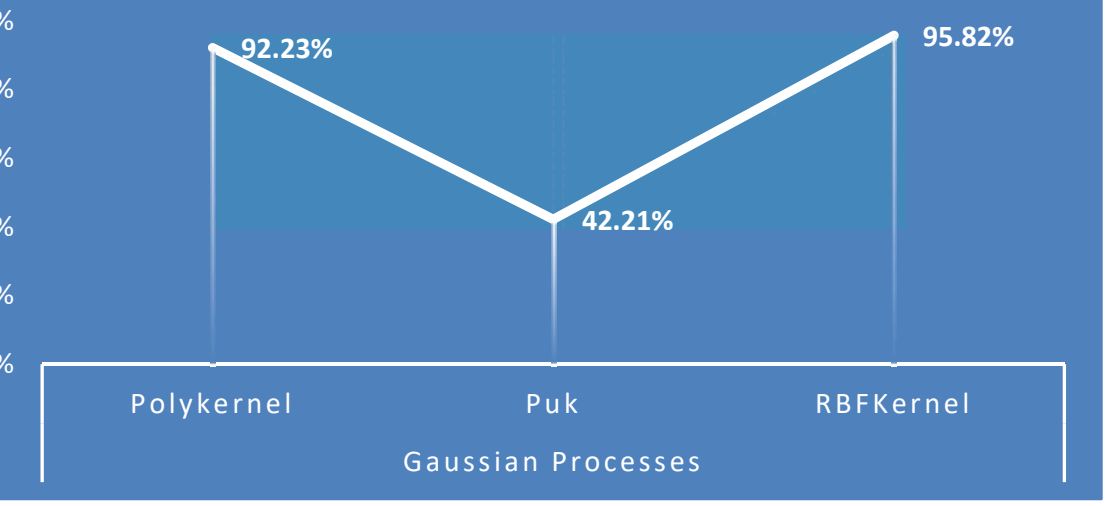

Figure 3: Gaussian Processes with Various Kernels Vs RRSE

The above diagram shows that the lowest root relative squared error value is $42.21 \%$ which is produced by Gaussian Processes with Puk kernel. Others are Gaussian with Polykernel produces $92.23 \%$ and Gaussian with RBFKernel produces $95.82 \%$.

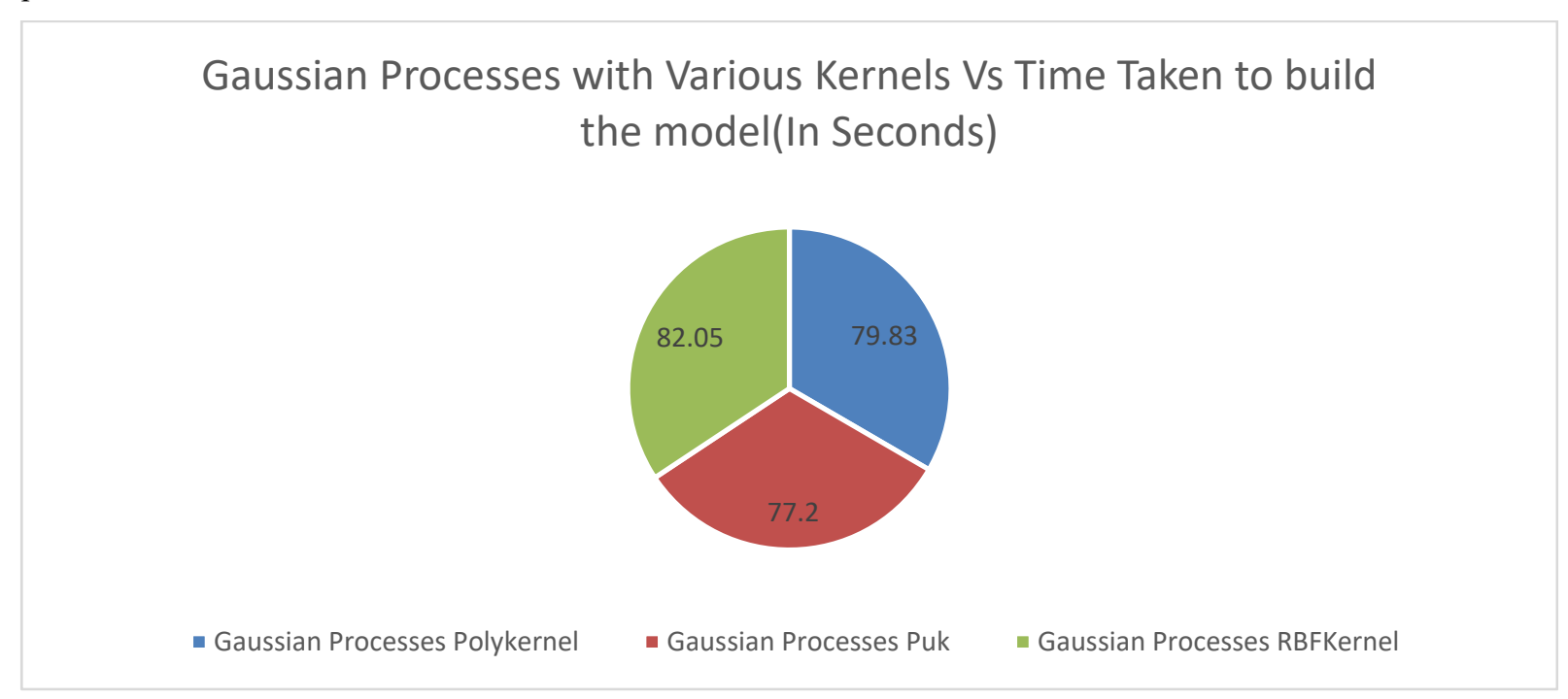

Figure 3: Gaussian Processes with Various Kernels Vs Time taken to build the model.

The above diagram shows that the Gaussian Process with Puk kernel has taken the time consumption is 77.2 seconds. Which is comparatively lowest than others.

\section{Conclusion}

This research work concludes that the optimal solution has produced by the Gaussian Processes with Puk kernel. Because all the measurements like correlation coefficient, Root relative squared error, Root mean squared error, mean absolute error mean squared error, etc,. are optimal solutions has given by this model. Other models are giving comparatively lowest optimal results for this research. So that this research recommends that the Gaussian process with Puk kernel machine learning approach gives an optimal solutions. 


\section{References}

[1] Jiazhen Cai, Xuan Chu, Kun Xu, Hongbo Li, Machine learning-driven new material discovery, Nanoscale Adv., 2020,2, 3115-3130

[2] M. I. Jordan and T. M. Mitchell, Science, 2015, 349, 255-260.

[3] E. Lopez, D. Gonzalez, J. V. Aguado, E. Abisset-Chavanne, E. Cueto, C. Binetruy and F. Chinesta, Arch. Comput. Methods Eng., 2016, 25, 59-68.

[4] W. Lu, R. Xiao, J. Yang, H. Li and W. Zhang, J. Materiomics, 2017, 3, 191-201.

[5] P. Raccuglia, K. C. Elbert, P. D. Adler, C. Falk, M. B. Wenny, A. Mollo, M. Zeller, S. A. Friedler, J. Schrier and A. J. Norquist, Nature, 2016, $533,73-76$

[6] X. Yang, J. Wang, J. Ren, J. Song, Z. Wang, Z. Zeng, X. Zhang, S. Huang, P. Zhang and H. Lin, Chinese Journal of Computational Physics, 2017, 34, 697-704.

[7] H. Lin, J. Zheng, L. Yuan and P. Feng, Energy Storage Sci. Technol., 2017, 6, 990-999

[8] Jordan, M. I.., \& Mitchell, T. M.. Machine learning: trends, perspectives, and prospects. Science 349, 255-260 (2015).

[9] Agrawal, A. \& Choudhary, A. Perspective: materials informatics and big data: realization of the fourth paradigm of science in materials science. APL Mater. 4, 053208 (2016).

[10] Seko, A., Hayashi, H., Nakayama, K., Takahashi, A. \& Tanaka, I. Representation of compounds for machine-learning prediction of physical properties. Phys. Rev. B 95, 144110 (2017).

[11] Medasani, B. et al. Predicting defect behavior in B2 intermetallics by merging ab initio modeling and machine learning. npj Comput. Mater. 2, 1 (2016).

[12] Chi, C. et al. Accurate force field for molybdenum by machine learning large materials data. Phys. Rev. Mater 1, 043603 (2017).

[13] Li, Z., Wang, S., Chin, W. S., Achenie, L. E. \& Xin, H. High-throughput screening of bimetallic catalysts enabled by machine learning. J. Mater. Chem. A 5, 24131-24138 (2017).

[14] Ulissi, Z. W., Medford, A. J., Bligaard, T. \& Nørskov, J. K. To address surface reaction network complexity using scaling relations machine learning and DFT calculations. Nat. Commun. 8, 14621 (2016).

[15] Raccuglia, P. et al. Machine-learning-assisted materials discovery using failed experiments. Nature 553, 73-77 (2016).

[16] Venkatesh Babu, R., Ayyappan, G., Kumaravel, A. Novel ensemble approaches to model macroscopic material behavior using micromechanical simulations, International Journal of Scientific and Technology Research, 2019, 8(11), pp. $2560-2564$.

[17] Cheng, H.-M., Wang, F.-M., Chu, J. P., Hwang, B.-J., Rick, J., and Chou, H.-L. (2017). Developing multivariate linear regression models to predict the electrochemical performance of lithium ion batteries based on material property parameters. J. Electrochem. Soc. 164, A1393A1400.

[18] Gola, J., Britz, D., Staudt, T., Winter, M., Schneider, A. S., Ludovici, M., et al. (2018). Advanced microstructure classification by data mining methods.

[19] Ying Zhang and Chen Ling ,A strategy to apply machine learning to small datasets in materials science,npj Computational Materials (2018) 4:25 ; doi:10.1038/s41524-018-0081-Z. 